\title{
Serotonergic System Does Not Contribute to the Hypothermic Action of Acetaminophen
}

\author{
Akihiro Fukushima, Wakana Sekiguchi, Kizuku Mamada, Yumi Tohma, and Hideki Ono* \\ Laboratory of Clinical Pharmacy and Pharmacology, Faculty of Pharmacy, Musashino University; 1-1-20 \\ Shinmachi, Nishitokyo, Tokyo 202-8585, Japan. \\ Received September 13, 2016; accepted November 21, 2016; advance publication released online December 3, 2016
}

\begin{abstract}
Acetaminophen (AcAP), a widely-used antipyretic and analgesic drug, has been considered to exert its effects via central mechanisms, and many studies have demonstrated that the analgesic action of AcAP involves activation of the serotonergic system. Although the serotonergic system also plays an important role in thermoregulation, the contribution of serotonergic activity to the hypothermic effect of AcAP has remained unclear. In the present study, we examined whether the serotonergic system is involved in AcAP-induced hypothermia. In normal mice, AcAP (300 mg/kg, intraperitoneally (i.p.)) induced marked hypothermia (ca. $-4^{\circ} \mathrm{C}$ ). The same dose of AcAP reduced pain response behavior in the formalin test. Pretreatment with the serotonin synthesis inhibitor DL-p-chlorophenylalanine (PCPA, 300 mg/kg/d, i.p., 5 consecutive days) substantially decreased serotonin in the brain by $70 \%$ and significantly inhibited the analgesic, but not the hypothermic action of AcAP. The same PCPA treatment significantly inhibited the hypothermia induced by the selective serotonin reuptake inhibitor fluoxetine hydrochloride $\left(20 \mathrm{mg} / \mathrm{kg}\right.$, i.p.) and the serotonin $5-\mathrm{HT}_{2}$ receptor antagonist cyproheptadine hydrochloride $(3 \mathrm{mg} / \mathrm{kg}$, i.p.). The lower doses of fluoxetine hydrochloride $(3 \mathrm{mg} / \mathrm{kg}$, i.p.) and cyproheptadine hydrochloride $(0.3 \mathrm{mg} / \mathrm{kg}$, i.p.) did not affect the AcAP-induced hypothermia. These results suggest that, in comparison with its analgesic effect, the hypothermic effect of AcAP is not mediated by the serotonergic system.
\end{abstract}

Key words acetaminophen; hypothermia; serotonin; fluoxetine; cyproheptadine; analgesia

Acetaminophen (AcAP) is a well-established antipyretic and analgesic drug widely used in many countries. AcAP has only a weak anti-inflammatory effect, and has been considered to exert its effects via mechanisms that are distinct from those of non-steroidal anti-inflammatory drugs (NSAIDs). AcAP can readily diffuse into the central nervous system, ${ }^{1-3)}$ and central administration elicits antinociceptive effects. ${ }^{4,5}$ Although AcAP does not act on specific receptors or channels ${ }^{5,6)}$ it has been reported to increase the level of serotonin (5-HT) in some brain areas, including the pontine nucleus ${ }^{7)}$ and hypothalamus. ${ }^{8)}$ Consistent with these findings, depletion of serotonin and central administration of serotonergic antagonists inhibit the antinociceptive effect of AcAP in rats and mice ${ }^{5,7,9-11)}$ Also in humans, tropisetron and granisetron block the analgesic effect of AcAP. ${ }^{12,13)}$ In this context, activation of the descending serotonergic system has been considered to contribute to the antinociceptive effect of AcAP.

AcAP reduces core body temperature in normothermic mice ${ }^{4,14-17)}$ and humans. ${ }^{18)}$ It has been suggested that induction of hypothermia by AcAP would be effective for neuroprotection after cardiac arrest or stroke (therapeutic hypothermia). ${ }^{19-21)}$ It has also been reported that AcAP-induced hypothermia can be inhibited by genetic deletion of cyclooxygenase- ${ }^{15)}$ (but see Li et al. ${ }^{16)}$ ) and transient receptor potential ankyrin 1 (TRPA1). ${ }^{14)}$ While the importance of serotonin in the analgesic effect of AcAP has been suggested, the contribution of serotonin to AcAP-induced hypothermia has not been reported. The serotonergic system is also involved in thermoregulation. Clinically, ingestion of an overdose of serotonergic antidepressants causes life-threatening hyperthermia (the so-called serotonin syndrome), and cyproheptadine, an antihistaminergic drug with antiserotonergic properties, has been used for management of this syndrome. ${ }^{22)}$ In rodents, pharmacological activation of $5-\mathrm{HT}_{1 \mathrm{~A}}{ }^{23)}$ central $5-\mathrm{HT}_{3}{ }^{24)}$ and central $5-\mathrm{HT}_{7}$ receptors $^{25)}$ induces hypothermia. Fluoxetine, a selective serotonin reuptake inhibitor, potentiates hypothermia induced by delta- and kappa-opioid receptor agonists. ${ }^{26,27)}$ It has also been shown that an increase in the extracellular level of serotonin evokes hypothermia in mice, and that further excess of serotonin evokes, in turn, hyperthermia. ${ }^{28)}$ Although the involvement of serotonin in thermoregulation is complex, these reports nevertheless suggest that AcAP induces hypothermia through activation of the serotonergic system.

In the present study, we examined the hypothermic and analgesic effects of AcAP in mice pretreated with the tryptophan hydroxylase inhibitor DL- $p$-chlorophenylalanine (PCPA). In order to confirm that PCPA can inhibit the hypothermic effects of other drugs, we also examined the effect of PCPA treatment on the hypothermia induced by fluoxetine and cyproheptadine.

\section{MATERIALS AND METHODS}

Materials The drugs used in this study were acetaminophen (AcAP; Iwaki Seiyaku, Tokyo, Japan), DL-p-chlorophenylalanine (PCPA; Nacalai Tesque, Kyoto, Japan), fluoxetine hydrochloride (Eli Lilly, Indianapolis, IN, U.S.A.), and cyproheptadine hydrochloride (Merck-Banyu, Tokyo, Japan). AcAP was dissolved in $20 \%$ (v/v) propylene glycol solution. Fluoxetine hydrochloride and cyproheptadine hydrochloride were dissolved in distilled water (D.W.). All drugs were injected intraperitoneally (i.p.) at $0.1 \mathrm{~mL} / 10 \mathrm{~g}$ bodyweight.

Animals Five- to six-week-old male ddY mice (SLC, Shizuoka, Japan) were used for this study. Before experiments, 
the mice were kept for at least $7 \mathrm{~d}$ under a 12-h light/dark cycle with water and food available ad libitum. All of the experimental protocols used here were approved by the Animal Care and Use Committee of Musashino University. All experiments were conducted in accordance with the guidelines of the Japanese Pharmacological Society.

Measurement of Rectal Temperature The experimental room was maintained at $24-26^{\circ} \mathrm{C}$, and measurement of body temperature was conducted as described previously. ${ }^{29)}$ Briefly, each mouse was held loosely in a small cloth bag, and its core body temperature was measured every $10 \mathrm{~min}$ using a digital thermometer with a resolution of $0.1^{\circ} \mathrm{C}$ (AD-5625; A\&D, Tokyo, Japan). The thermometer probe was inserted $25 \mathrm{~mm}$ into the rectum. Mice whose rectal temperature before drug administration was below $37^{\circ} \mathrm{C}$ were not used for experiments. Drug effects were expressed as the decrease in body temperature $\left(\Delta^{\circ} \mathrm{C}\right)$.

Formalin Test Mice were placed individually in plexiglass cages and allowed to acclimate to their environment for $30 \mathrm{~min}$. Twenty microliters of $1 \%$ formaldehyde $(2.5 \%$ forma- lin in D.W.) was injected into the plantar surface of the right hindpaw using a 30-gauge needle. The incidence of formalininduced nociceptive behavior characterized by licking/biting of the affected paw was measured for $60 \mathrm{~min}$. Either AcAP or vehicle was administered i.p. $20 \mathrm{~min}$ before the formalin injection. The first and second phases were recorded during $0-10$ and $10-40 \mathrm{~min}$ after injection of formalin, respectively. Time spent performing the licking/biting behavior in each 5-min block was recorded continuously.

Depletion of Serotonin To deplete central serotonin, PCPA $(300 \mathrm{mg} / \mathrm{kg}$, i.p.) was administered for five consecutive days. ${ }^{30)}$ PCPA was suspended in $0.5 \%$ carboxymethylcellulose sodium solution (CMC). Control mice were injected with CMC alone. All measurements were made a day after the last treatment with either PCPA or CMC by experimenters who were blinded to the treatment groups.

LC-MS/MS Analysis of Monoamines in the Mouse Brain Monoamine contents in mouse brain were analyzed by liquid chromatography coupled with tandem mass spectrometry (LC-MS/MS) ${ }^{31)}$ Mouse brains were homogenized in the solu-
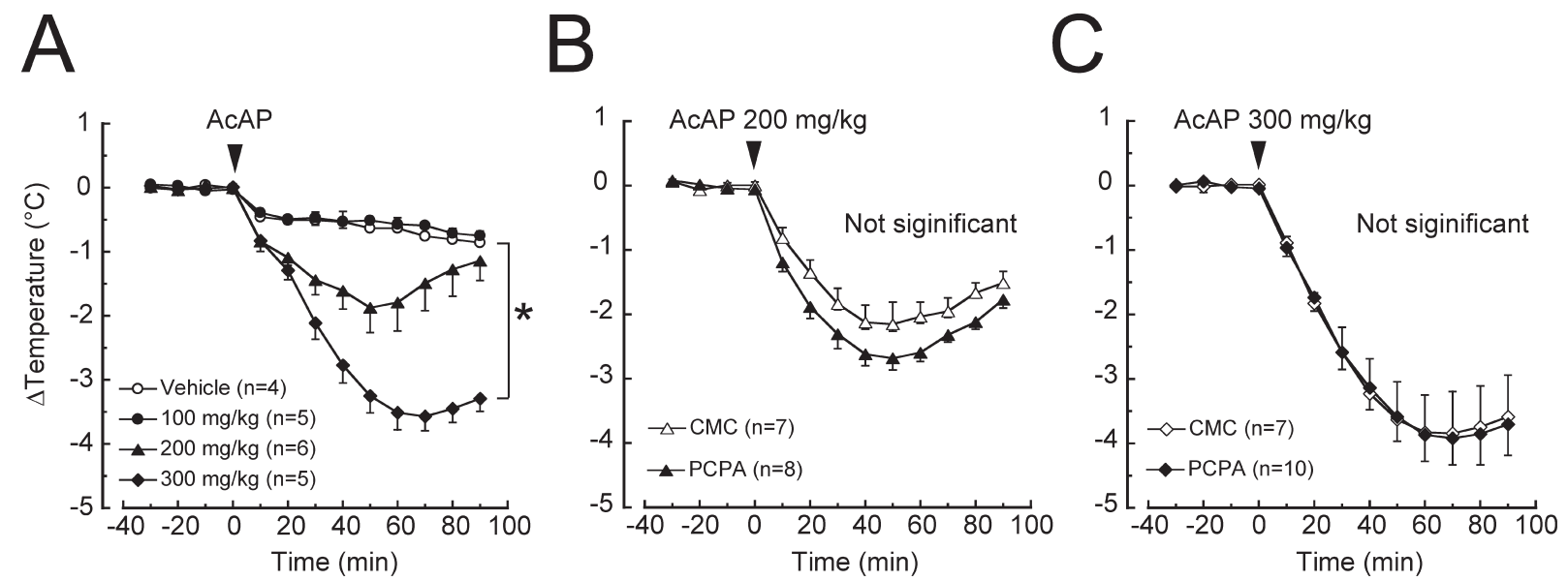

Fig. 1. Hypothermic Effect of Acetaminophen

(A) Acetaminophen-evoked hypothermia in naive mice. Two-way repeated measure ANOVA showed significant main effects of dose $[F(3,16)=19.751 ; p<0.001]$ and time $[F(9,144)=67.520 ; p<0.001]$ with an interaction between these factors $[F(27,144)=17.574 ; p<0.001]$. Acetaminophen $(300 \mathrm{mg} / \mathrm{kg})$ significantly reduced body temperature compared with the vehicle-treated group $(* p<0.05$, Dunnett's two-tailed $t$-test). (B) Hypothermic effect of acetaminophen (200 mg/kg) in PCPA-treated mice. Two-way repeated measure ANOVA showed a significant main effect of time $[F(9,117)=88.626 ; p<0.001]$. But there was neither a significant main effect of dose $[F(1,13)=3.715 ; p>0.05]$ nor an interaction between these factors $[F(9,117)=0.925 ; p>0.05]$. (C) Hypothermic effect of acetaminophen $(300 \mathrm{mg} / \mathrm{kg})$ in PCPA-treated mice. Two-way repeated measure ANOVA showed main effect of time $[F(9,135)=77.913 ; p<0.001]$. There was neither a significant main effect of dose $[F(1,15)=0.003 ; p>0.05]$ nor an interaction between these factors $[F(9,135)=0.065 ; p>0.05]$. Each point represents the mean \pm S.E.M.
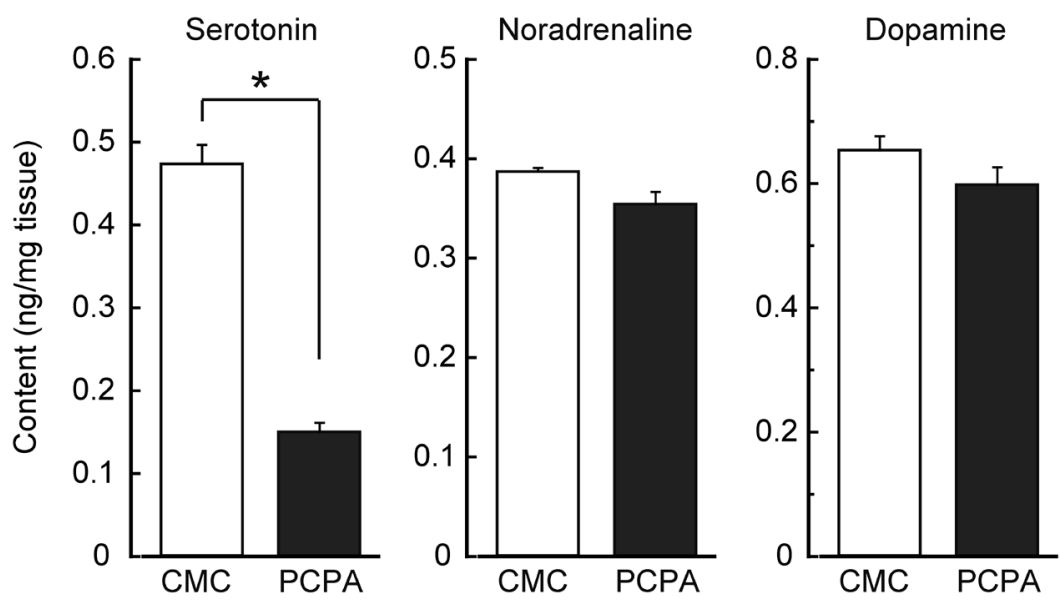

Fig. 2. The Brain Monoamine Contents after the PCPA Treatment

Data were obtained from four mice in each group. Each column represents the mean \pm S.E.M. The Student's two-tailed $t$-test was used for statistical analysis $(* p<0.05)$. 
tion containing $0.05 \%$ Triton- $\mathrm{X}$ and $10 \mathrm{~mm}$ ammonium formate (pH 4.0, $1 \mathrm{~mL}$ per $100 \mathrm{mg}$ tissue). An equal volume of ice-cold chloroform-methanol $(2: 1, \mathrm{v} / \mathrm{v})$ containing $6.6 \mu \mathrm{M} 3,4$-dihydroxybenzylamine hydrobromide (DHBA, Sigma, St. Louis, MO, U.S.A.) as internal standard was added to the homogenate and centrifuged at $1500 \times \boldsymbol{g}$ for $30 \mathrm{~min}$ at $4^{\circ} \mathrm{C}$. The upper phase was collected and centrifuged at $15000 \times \boldsymbol{g}$ at $4^{\circ} \mathrm{C}$. Serotonin, noradrenaline and dopamine were extracted from the supernatant with a Monospin PBA column (GL Sciences, Tokyo, Japan). Samples were analyzed on a Shimadzu LC-MS/MS system (LCMS-8040; Kyoto, Japan) with a COSMOSIL PBr column (2.0 mm i.d. $\times 150 \mathrm{~mm}$, Nacalai Tesque, Kyoto, Japan). The mobile phases were $10 \mathrm{~mm}$ ammonium formate $(\mathrm{pH} 4.0)$ and acetonitrile. The flow rate was $0.40 \mathrm{~mL} / \mathrm{min}$. The acetonitrile content was $0 \%$ until $1.5 \mathrm{~min}$, then increased linearly to $60 \%$ over $5.5 \mathrm{~min}$, followed by an equilibration period at $0 \%$ for $4 \mathrm{~min}$. The electrospray ionization in positive mode was performed for the quantification, using the multiple reaction monitoring (MRM) of the protonated molecular ion to predominant product ion pairs at $\mathrm{m} / \mathrm{z} 177.1 \rightarrow 160.1$ for serotonin,
$169.9 \rightarrow 152.1$ for noradrenaline, $154.1 \rightarrow 137.0$ for dopamine and $139.9 \rightarrow 123.0$ for DHBA. All samples were duplicated.

Statistical Analysis All data were expressed as the mean \pm standard error of the mean (S.E.M.). Parametric multiple comparisons of the overall effect of treatments (0-90 min) on body temperature were made by a two-way repeated measure ANOVA with Dunnett's two-tailed $t$-test using IBM SPSS Statistics 24.0. In the formalin test, the twotailed Mann-Whitney $U$-test was used to compare total licking/biting time during the first and second phases of control and treated groups. The Student's two-tailed $t$-test was used to compare the body weight, the basal rectal temperature and the monoamine contents in the brain of control and treated groups. Differences at $p<0.05$ (two-tailed) were considered to be significant.

\section{RESULTS}

Serotonin Depletion Does Not Alter Hypothermia Induced by Acetaminophen AcAP at $300 \mathrm{mg} / \mathrm{kg}$ (i.p.) signifi-

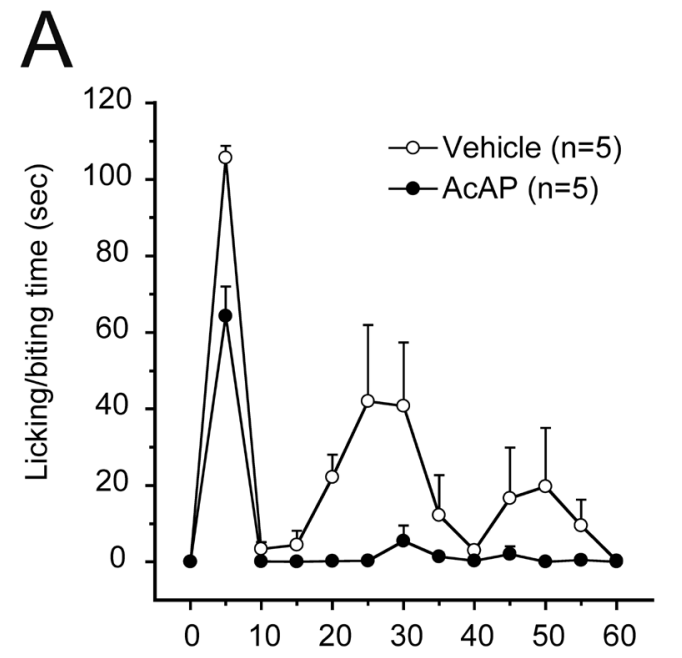

Time after formalin injection ( $\mathrm{min})$

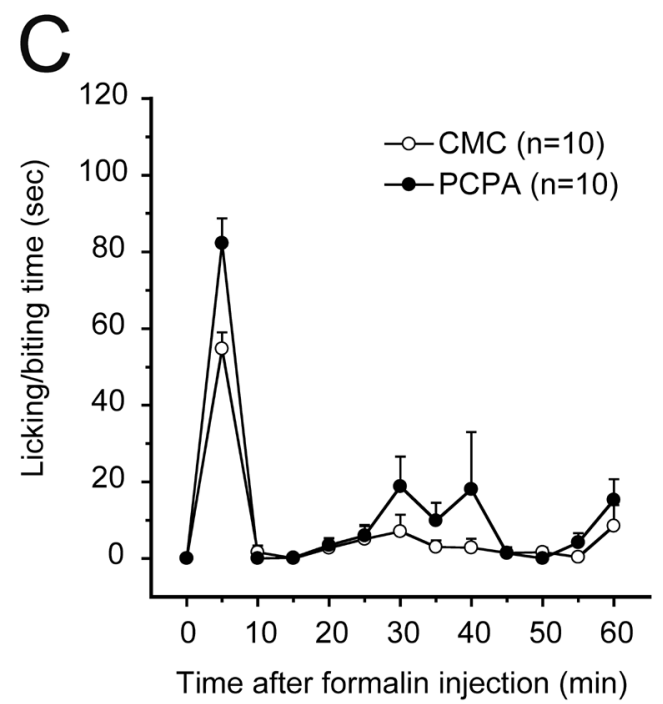

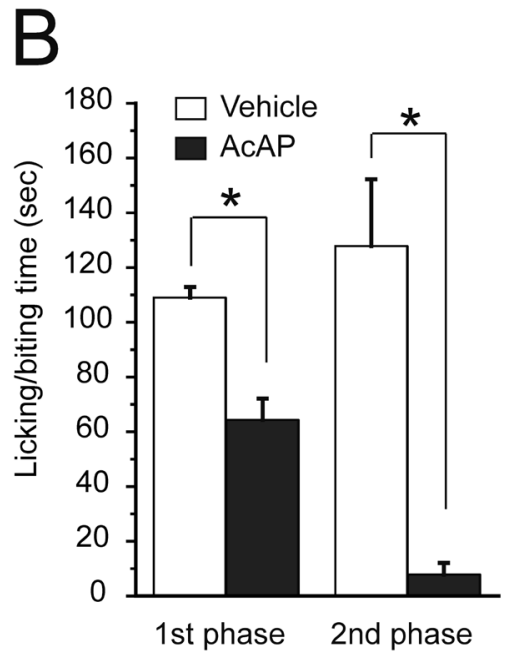

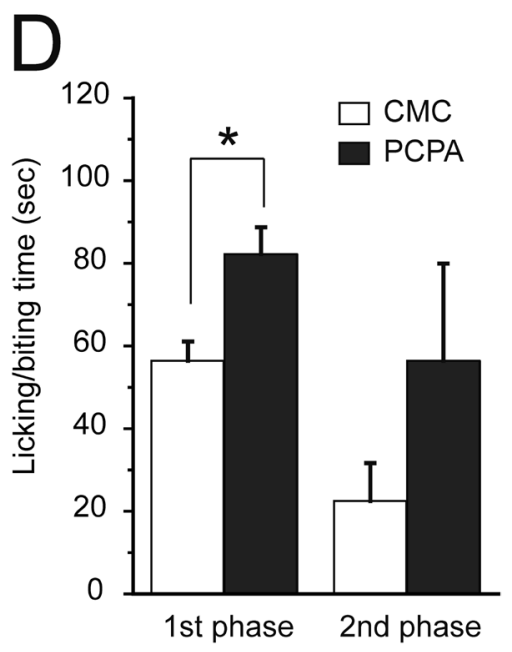

Fig. 3. Analgesic Effect of Acetaminophen in Naive (A, B) and PCPA-Treated Mice (C, D)

In $\mathrm{C}$ and $\mathrm{D}$, mice were pretreated with PCPA or CMC. Acetaminophen $(300 \mathrm{mg} / \mathrm{kg}$, i.p.) was administered $20 \mathrm{~min}$ before formalin injection. Formalin was injected at time zero. Time-course graphs (A, C) showing licking/biting behavior(s) in consecutive 5-min blocks. Columns (B, D) showing total licking/biting behavior(s) during the first $(0-10 \mathrm{~min})$ and second $(10-40 \mathrm{~min})$ phase. Each point or column represents the mean \pm S.E.M. ${ }^{*} p<0.05$ versus control group (the two-tailed Mann-Whitney $U$-test). 

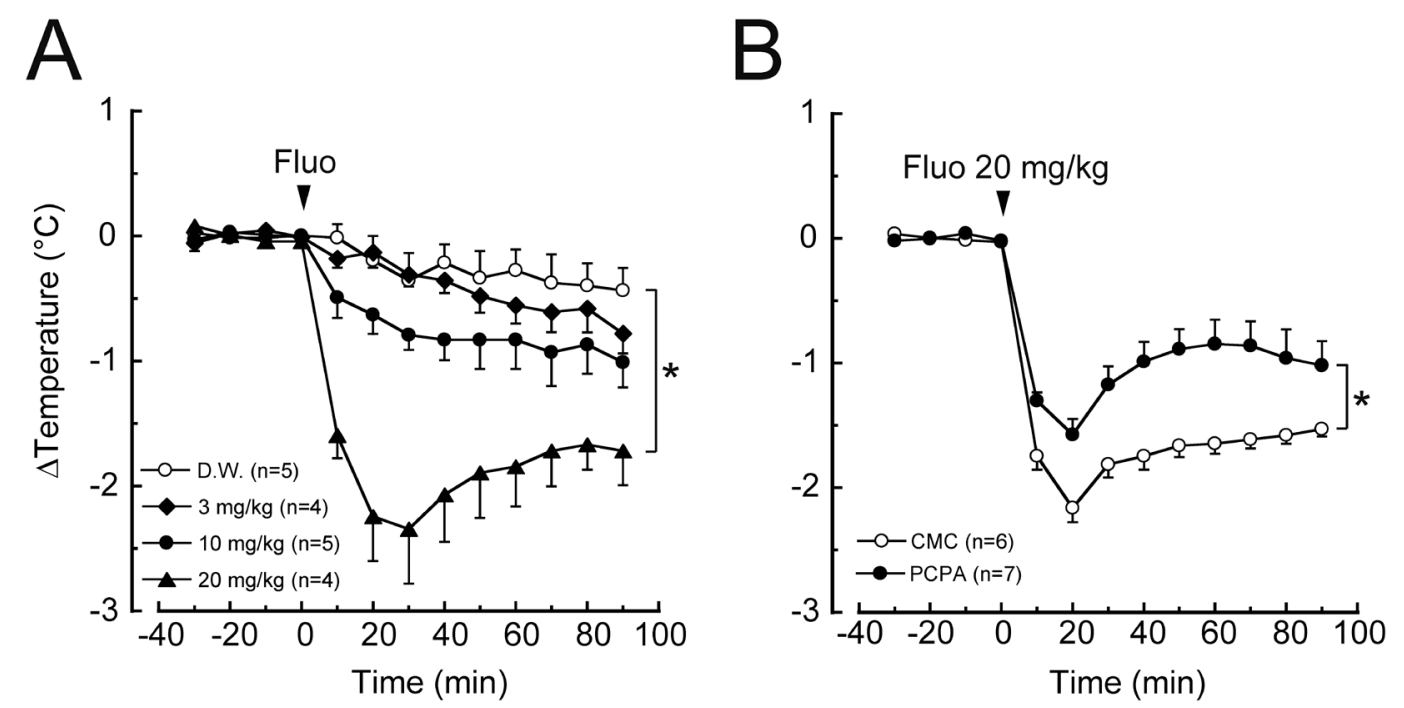

Fig. 4. Hypothermic Effect of Fluoxetine Hydrochloride in Naive (A) and PCPA-Treated Mice (B)

In A, two-way repeated measure ANOVA showed significant main effects of dose $[F(3,14)=13.886 ; p<0.001]$ and time $[F(9,126)=22.077 ; p<0.001)]$ with an interaction between these factors $[F(27,126)=4.860 ; p<0.001]$. Fluoxetine hydrochloride $(20 \mathrm{mg} / \mathrm{kg})$ significantly reduced body temperature compared with the D.W. group $(p<0.001$, Dunnett's two-tailed $t$-test, indicated with an asterisk). In B, two-way repeated measure ANOVA showed significant main effects of treatment $[F(1,11)=6.698 ; p<0.05$, indicated with an asterisk] and time $[F(9,99)=43.316 ; p<0.001]$ with an interaction between these factors $[F(9,99)=2.641 ; p<0.05]$. Each point represents the mean \pm S.E.M. Fluo, fluoxetine hydrochloride.
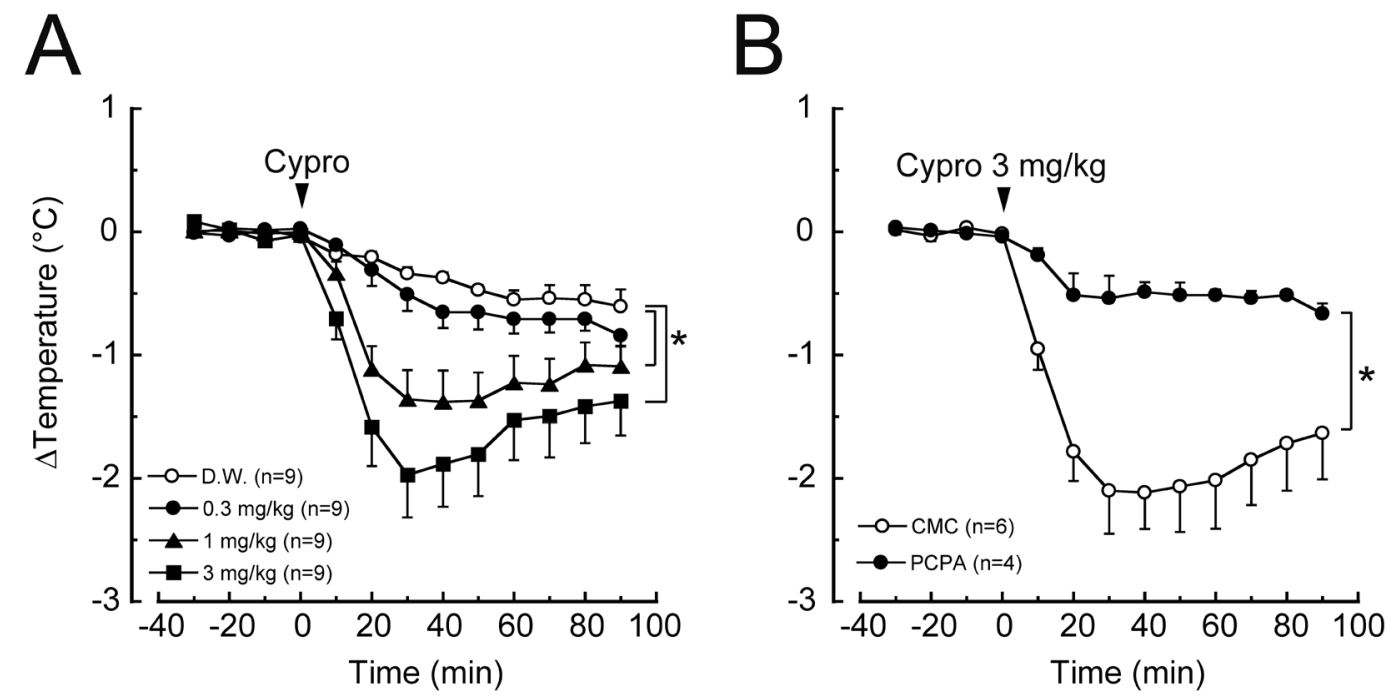

Fig. 5. Hypothermic Effect of Cyproheptadine Hydrochloride in Naive (A) and PCPA-Treated Mice (B)

In A, two-way repeated measure ANOVA showed main effects of dose $[F(3,32)=7.769 ; p<0.001]$ and time $[F(9,288)=56.329 ; p<0.001]$ with an interaction between these factors $[F(27,288)=6.063 ; p<0.001]$. Cyproheptadine hydrochloride $(1,3 \mathrm{mg} / \mathrm{kg})$ significantly reduced body temperature compared with the D.W. group $(p<0.05$, Dunnett's two-tailed $t$-test, indicated with an asterisk). In B, two-way repeated measure ANOVA revealed a significant main effect of treatment $[F(1,8)=39.619 ; p<0.001$, indicated with an asterisk] on AcAP-induced hypothermia. There was also a significant main effect of time $[F(9,72)=11.460 ; p<0.001]$ with an interaction between these factors $[F(9,72)=4.187 ; p<0.001]$. Each point represents the mean \pm S.E.M. Cypro, cyproheptadine hydrochloride.

cantly reduced the body temperature of mice (Fig. 1A). AcAP at $200 \mathrm{mg} / \mathrm{kg}$ also reduced the body temperature although the effect was not significant $(p=0.064)$. The hypothermic effects of AcAP were not affected by PCPA treatment [Fig. $1 \mathrm{~B}(200 \mathrm{mg} / \mathrm{kg}), \mathrm{C}(300 \mathrm{mg} / \mathrm{kg})]$. The PCPA treatment also did not result in a change of body weight (CMC group $28.6 \pm 0.9 \mathrm{~g}$, $n=14$; PCPA group 27.5 $\pm 0.9 \mathrm{~g}, n=18 ; \quad p>0.05$, Student's two-tailed $t$-test) or basal rectal temperature (CMC group $38.1 \pm 0.1^{\circ} \mathrm{C}, n=14$; PCPA group $38.1 \pm 0.1^{\circ} \mathrm{C}, n=18 ; p>0.05$, Student's two-tailed $t$-test). The treatment with PCPA reduced the serotonin content in the brain to $31.8 \%$ of that in control mice treated with vehicle $(\mathrm{CMC})$ alone, whereas the simultaneously measured noradrenaline and dopamine contents were unchanged (Fig. 2).
Serotonin Depletion Partially Reverses the Analgesic Effect of Acetaminophen AcAP at $300 \mathrm{mg} / \mathrm{kg}$ (i.p.) reduced licking/biting behavior in both the first and second phases of the formalin test (Figs. 3A, B). The time of licking/biting in the first phase was significantly reversed by PCPA treatment (Figs. 3C, D). The licking/biting time in the second phase was slightly reversed.

Serotonin Depletion Attenuates Hypothermia Induced by Fluoxetine and Cyproheptadine Fluoxetine hydrochloride $(20 \mathrm{mg} / \mathrm{kg}$, i.p.) reduced body temperature significantly (Fig. 4A). The hypothermic effect of $20 \mathrm{mg} / \mathrm{kg}$ fluoxetine hydrochloride was significantly inhibited in the PCPA-treated mice (Fig. 4B). The PCPA treatment resulted in no change of body weight (CMC group 29.3 $\pm 0.6 \mathrm{~g}, n=6$; PCPA group 

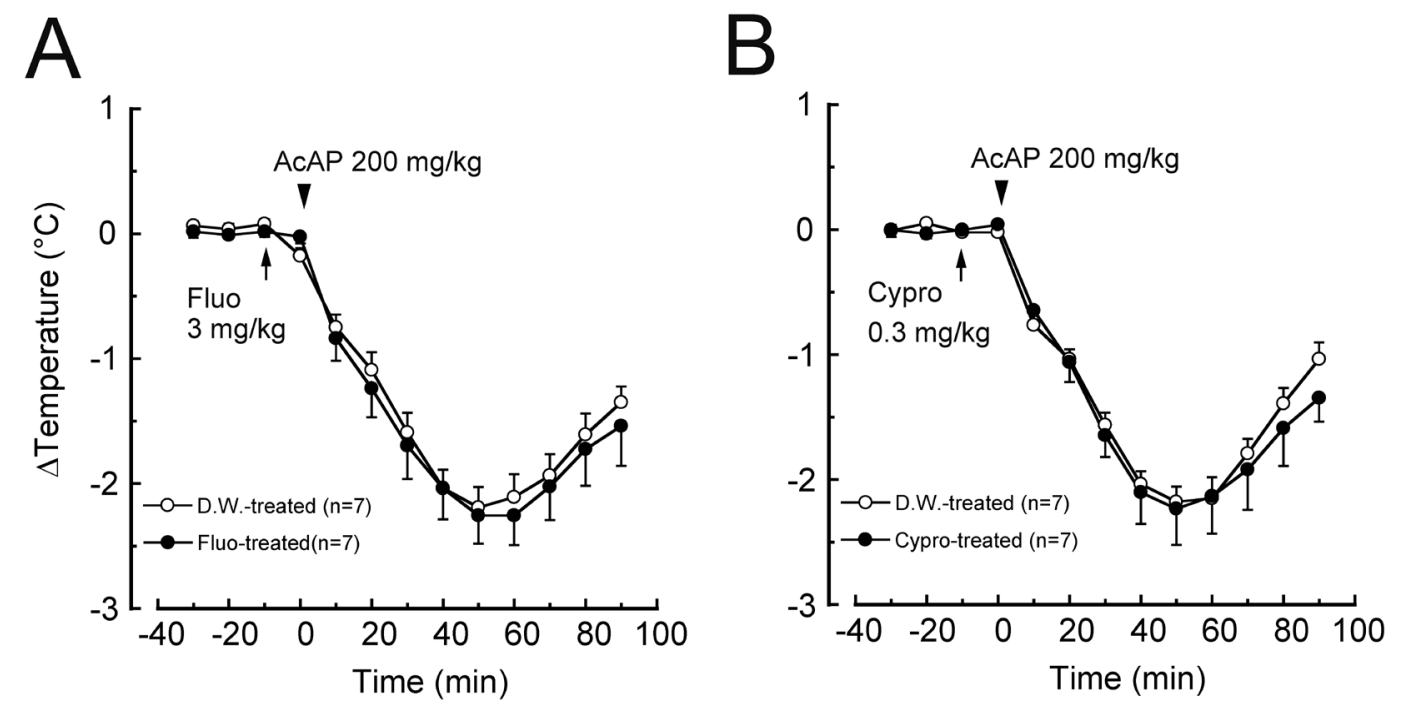

Fig. 6. Neither Fluoxetine nor Cyproheptadine Affects the Hypothermic Effect of Acetaminophen

(A) Fluoxetine hydrochloride ( $3 \mathrm{mg} / \mathrm{kg}$, i.p.) was administered $10 \mathrm{~min}$ before AcAP $(200 \mathrm{mg} / \mathrm{kg}$, i.p.). Two-way repeated measure ANOVA showed a significant main effect of time $[F(9,108)=88.689 ; p<0.001]$. There was neither a significant main effect of treatment $[F(1,12)=0.102 ; p>0.05]$ nor an interaction between these factors $[F(9,108)=0.451 ; p>0.05]$. (B) Cyproheptadine hydrochloride $(0.3 \mathrm{mg} / \mathrm{kg}$, i.p.) was administered $10 \mathrm{~min}$ before AcAP (200 mg $/ \mathrm{kg}$, i.p.). Two-way repeated measure ANOVA showed a significant main effect of time $[F(9,108)=87.576 ; p<0.001]$. There was neither a significant main effect of treatment $[F(1,12)=0.095 ; p>0.05]$ nor an interaction between these factors $[F(9,108)=0.674 ; p>0.05]$. Each point represents the mean \pm S.E.M. Fluo, fluoxetine hydrochloride; Cypro, cyproheptadine hydrochloride.

$28.3 \pm 0.5 \mathrm{~g}, n=7 ; p>0.05$, Student's two-tailed $t$-test). Basal rectal temperature of PCPA-treated mice was slightly lower than that of CMC-treated mice (CMC group 38.6 $\pm 0.1^{\circ} \mathrm{C}, n=6$; PCPA group $38.1 \pm 0.1^{\circ} \mathrm{C}, n=7 ; p<0.05$, Student's two-tailed $t$-test).

Cyproheptadine hydrochloride $(0.3-3 \mathrm{mg} / \mathrm{kg}$, i.p.) reduced body temperature dose-dependently (Fig. 5A). The hypothermic effect of $3 \mathrm{mg} / \mathrm{kg}$ cyproheptadine hydrochloride was strongly inhibited in the PCPA-treated mice (Fig. 5B). The PCPA treatment did not result in a change of body weight (CMC group $31.5 \pm 1.4 \mathrm{~g}, n=6$; PCPA group $32.2 \pm 1.5 \mathrm{~g}, n=4$; $p>0.05$, Student's two-tailed $t$-test) or basal rectal temperature (CMC group $38.2 \pm 0.2^{\circ} \mathrm{C}, n=6$; PCPA group $38.1 \pm 0.2^{\circ} \mathrm{C}, n=4$; $p>0.05$, Student's two-tailed $t$-test).

We next examined the interaction of fluoxetine and cyproheptadine with AcAP. Neither pre-administration of fluoxetine hydrochloride (3 mg/kg, i.p., Fig. 6A) nor cyproheptadine hydrochloride $(0.3 \mathrm{mg} / \mathrm{kg}$, i.p., Fig. $6 \mathrm{~B})$ affected the hypothermic effect of AcAP $(200 \mathrm{mg} / \mathrm{kg})$.

\section{DISCUSSION}

In the present study, we set out to determine whether the hypothermic action of acetaminophen involves activation of the serotonergic system, and found that serotonin depletion by PCPA reversed the analgesic, but not the hypothermic effect of AcAP. These results indicate that serotonin is not involved in AcAP-induced hypothermia in mice.

The degree and time course of AcAP-induced hypothermia were consistent with results obtained in earlier studies. ${ }^{14-16)}$ It has been suggested that the hypothermic effect of AcAP is unrelated to the production of reactive oxygen species by AcAP and its hepatotoxicity. ${ }^{17}$ ) The inhibitory effect of PCPA on AcAP-induced analgesia in the formalin test is also consistent with the results of an earlier study. ${ }^{7)}$ Consistent with previous reports, ${ }^{30,31)}$ the PCPA treatment protocol used in the present study markedly reduced the serotonin content of the central nervous system. The basal rectal temperature of the PCPAtreated mice was normal, suggesting that the lack of serotonin can be compensated by other thermoregulatory mechanisms. In this situation, the hypothermic effects of drugs that act on endogenous serotonin would be inhibited, and in fact we found that the hypothermia evoked by fluoxetine and cyproheptadine was inhibited in PCPA-treated mice. The fact that both the serotonin reuptake inhibitor and the serotonin antagonist evoked hypothermia would appear to be inconsistent, but might be explained by the difference in receptor subtypes and/or brain regions on which they act. Although the hypothermic mechanisms of fluoxetine and cyproheptadine require further investigation, the present results at least demonstrate that serotonin depletion by PCPA can inhibit the hypothermic actions of drugs other than AcAP. Furthermore, the lower doses of fluoxetine and cyproheptadine did not interact with the AcAP-evoked hypothermia. These results support the conclusion that the serotonergic system is dispensable for the hypothermic effect of AcAP.

It has been reported that AcAP $(200-400 \mathrm{mg} / \mathrm{kg})$ increases the serotonin level in the hypothalamus of rats and $\mathrm{K}^{+}$-evoked serotonin overflow from cortex slices by $30-40 \%{ }^{8)}$ However, it also has been shown that serotonin efflux in the hypothalamus of clorgiline-treated mice rises 11-fold when the body temperature is lowered by 5-hydroxytryptophan administration, ${ }^{28)}$ and thus the increase of brain serotonin by AcAP seems to be far from this level. The serotonin-non-dependence of AcAP-induced hypothermia suggests that the mechanism responsible for the hypothermic action of AcAP differs from that underlying the mechanism responsible for analgesia. AcAP is deacetylated in the liver and the resulting metabolite, $p$-aminophenol, is then converted to $N$-(4-hydroxyphenyl)-arachidonamide (AM404) in the brain through conjugation with arachidonic acids. ${ }^{32)}$ AM404 stimulates transient receptor potential vanilloid 1 (TRPV1) and endocannabinoid $\mathrm{CB}_{1}$ receptors in the brainstem and, as a result, activates the descending serotonergic system. ${ }^{33-35)}$ AM404 also evokes hypothermia in 
rats via TRPV1, ${ }^{36)}$ although Ayoub et al. ${ }^{37)}$ have reported that this AcAP-induced hypothermia is not inhibited in TRPV1knockout and $\mathrm{CB}_{1}$ receptor-knockout mice. Although the precise mechanism of AcAP-induced hypothermia was not clarified in the present study, AcAP might have another mode of action. Further understanding of the mechanisms of action of AcAP will provide the foundation for development of more effective hypothermic drugs and open the way for establishment of therapeutic hypothermia.

Conflict of Interest The authors declare no conflict of interest.

\section{REFERENCES}

1) Courad JP, Besse D, Delchambre C, Hanoun N, Hamon M, Eschalier A, Caussade F, Cloarec A. Acetaminophen distribution in the rat central nervous system. Life Sci., 69, 1455-1464 (2001).

2) Bannwarth B, Netter P, Lapicque F, Gillet P, Péré P, Boccard E, Royer RJ, Gaucher A. Plasma and cerebrospinal fluid concentrations of paracetamol after a single intravenous dose of propacetamol. $\mathrm{Br}$. J. Clin. Pharmacol., 34, 79-81 (1992).

3) Davison C, Guy JL, Levitt M, Smith PK. The distribution of certain non-narcotic analgetic agents in the CNS of several species. $J$. Pharmacol. Exp. Ther., 134, 176-183 (1961).

4) Massey TE, Walker RM, McElligott TF, Racz WJ. Acetaminopheninduced hypothermia in mice: evidence for a central action of the parent compound. Toxicology, 25, 187-200 (1982).

5) Pelissier T, Alloui A, Caussade F, Dubray C, Cloarec A, Lavarenne J, Eschalier A. Paracetamol exerts a spinal antinociceptive effect involving an indirect interaction with 5-hydroxytryptamine3 receptors: in vivo and in vitro evidence. J. Pharmacol. Exp. Ther., 278, 8-14 (1996).

6) Raffa RB, Codd EE. Lack of binding of acetaminophen to 5-HT receptor or uptake sites (or eleven other binding/uptake assays). Life Sci., 59, PL37-PL40 (1996).

7) Pini LA, Sandrini M, Vitale G. The antinociceptive action of paracetamol is associated with changes in the serotonergic system in the rat brain. Eur. J. Pharmacol., 308, 31-40 (1996).

8) Courade JP, Caussade F, Martin K, Besse D, Delchambre C, Hanoun N, Hamon M, Eschalier A, Cloarec A. Effects of acetaminophen on monoaminergic systems in the rat central nervous system. Naunyn Schmiedebergs Arch. Pharmacol., 364, 534-537 (2001).

9) Dogrul A, Seyrek M, Akgul EO, Cayci T, Kahraman S, Bolay $\mathrm{H}$. Systemic paracetamol-induced analgesic and antihyperalgesic effects through activation of descending serotonergic pathways involving spinal 5-HT 7 receptors. Eur. J. Pharmacol., 677, 93-101 (2012).

10) Bonnefont J, Chapuy E, Clottes E, Alloui A, Eschalier A. Spinal 5-HT1A receptors differentially influence nociceptive processing according to the nature of the noxious stimulus in rats: effect of WAY-100635 on the antinociceptive activities of paracetamol, venlafaxine and 5-HT. Pain, 114, 482-490 (2005).

11) Sandrini M, Pini LA, Vitale G. Differential involvement of central 5-HT1B and 5-HT3 receptor subtypes in the antinociceptive effect of paracetamol. Inflamm. Res., 52, 347-352 (2003).

12) Pickering G, Loriot M-A, Libert F, Eschalier A, Beaune P, Dubray C. Analgesic effect of acetaminophen in humans: first evidence of a central serotonergic mechanism. Clin. Pharmacol. Ther., 79, 371-378 (2006).

13) Pickering G, Estève V, Loriot M, Eschalier A, Dubray C. Acetaminophen reinforces descending inhibitory pain pathways. Clin. Pharmacol. Ther., 84, 47-51 (2008).

14) Gentry C, Andersson D, Bevan S. TRPA1 mediates the hypothermic action of acetaminophen. Sci. Rep., 5, 12771 (2015).
15) Ayoub SS, Botting RM, Goorha S, Colville-Nash PR, Willoughby DA, Ballou LR. Acetaminophen-induced hypothermia in mice is mediated by a prostaglandin endoperoxide synthase 1 gene-derived protein. Proc. Natl. Acad. Sci. U.S.A., 101, 11165-11169 (2004).

16) Li S, Dou W, Tang Y, Goorha S, Ballou LR, Blatteis CM. Acetaminophen: antipyretic or hypothermic in mice? In either case, PGHS-1b (COX-3) is irrelevant. Prostaglandins Other Lipid $\mathrm{Me}-$ diat., 85, 89-99 (2008).

17) Kanno S, Tomizawa A, Hiura T, Osanai Y, Kakuta M, Kitajima Y, Koiwai K, Ohtake T, Ujibe M, Ishikawa M. Melatonin protects on toxicity by acetaminophen but not on pharmacological effects in mice. Biol. Pharm. Bull., 29, 472-476 (2006).

18) Foster J, Mauger A, Thomasson K, White S, Taylor L. Effect of acetaminophen ingestion on thermoregulation of normothermic, non-febrile humans. Front. Pharmacol., 7, 54 (2016).

19) Cheung KW, Green RS, Magee KD. Systematic review of randomized controlled trials of therapeutic hypothermia as a neuroprotectant in post cardiac arrest patients. CJEM, 8, 329-337 (2006).

20) den Hertog HM, van der Worp HB, van Gemert HM, Algra A, Kappelle LJ, van Gijn J, Koudstaal PJ, Dippel DWJ, PAIS Investigators. The Paracetamol (Acetaminophen) In Stroke (PAIS) trial: a multicentre, randomised, placebo-controlled, phase III trial. Lancet Neurol., 8, 434-440 (2009).

21) Den Hertog HM, van der Worp HB, Tseng MC, Dippel DW. Cooling therapy for acute stroke. Cochrane Database Syst. Rev., CD001247 (2009).

22) Graudins A, Stearman A, Chan B, Kulig K. Treatment of the serotonin syndrome with cyproheptadine. J. Emerg. Med., 16, 615-619 (1998).

23) O'Connell MT, Sarna GS, Curzon G. Evidence for postsynaptic mediation of the hypothermic effect of 5-HT1A receptor activation. $B r$. J. Pharmacol., 106, 603-609 (1992).

24) Voronova IP, Naumenko VS, Khramova GM, Kozyreva TV, Popova NK. Central 5-HT3 receptor-induced hypothermia is associated with reduced metabolic rate and increased heat loss. Neurosci. Lett., 504, 209-214 (2011).

25) Naumenko VS, Kondaurova EM, Popova NK. On the role of brain 5-HT7 receptor in the mechanism of hypothermia: comparison with hypothermia mediated via 5-HT1A and 5-HT3 receptor. Neuropharmacology, 61, 1360-1365 (2011).

26) Rawls SM, Cowan A. Modulation of delta opioid-evoked hypothermia in rats by WAY 100635 and fluoxetine. Neurosci. Lett., 398, 319-324 (2006)

27) Nemmani KV, Gullapalli S, Ramarao P. Potentiation of kappaopioid receptor agonist-induced analgesia and hypothermia by fluoxetine. Pharmacol. Biochem. Behav., 69, 189-193 (2001).

28) Zhang G, Krishnamoorthy S, Ma Z, Vukovich NP, Huang X, Tao R. Assessment of 5-hydroxytryptamine efflux in rat brain during a mild, moderate and severe serotonin-toxicity syndrome. Eur. J. Pharmacol., 615, 66-75 (2009).

29) Ono H, Nagano Y, Matsunami N, Sugiyama S, Yamamoto S, Tanabe M. Oseltamivir, an anti-influenza virus drug, produces hypothermia in mice. Biol. Pharm. Bull., 31, 638-642 (2008).

30) Tanabe M, Tokuda Y, Takasu K, Ono K, Honda M, Ono H. The synthetic TRH analogue taltirelin exerts modality-specific antinociceptive effects via distinct descending monoaminergic systems. Br. J. Pharmacol., 150, 403-414 (2007).

31) Nakamoto $K$, Nishinaka $T$, Sato $N$, Aizawa $F$, Yamashita $T$, Mankura M, Koyama Y, Kasuya F, Tokuyama S. The activation of supraspinal GPR40/FFA1 receptor signalling regulates the descending pain control system. Br. J. Pharmacol., 172, 1250-1262 (2015).

32) Högestätt ED, Jönsson BG, Ermund A, Andersson DA, Björk H, Alexander JP, Cravatt BF, Basbaum AI, Zygmunt PM. Conversion of acetaminophen to the bioactive $N$-acylphenolamine AM404 via fatty acid amide hydrolase-dependent arachidonic acid conjugation in the nervous system. J. Biol. Chem., 280, 31405-31412 (2005). 
33) Mallet C, Daulhac L, Bonnefont J, Ledent C, Etienne M, Chapuy E, Libert F, Eschalier A. Endocannabinoid and serotonergic systems are needed for acetaminophen-induced analgesia. Pain, 139, 190-200 (2008).

34) Mallet $\mathrm{C}$, Barrière DA, Ermund A, Jönsson BG, Eschalier A, Zygmunt PM, Högestätt ED. TRPV1 in brain is involved in acetaminophen-induced antinociception. PLOS ONE, 5, e12748 (2010).

35) Barrière DA, Mallet C, Blomgren A, Simonsen C, Daulhac L, Libert F, Chapuy E, Etienne M, Högestätt ED, Zygmunt PM, Eschalier A. Fatty acid amide hydrolase-dependent generation of antinocicep- tive dug metabolites acting on TRPV1 in the brain. PLOS ONE, $\mathbf{8}$, e70690 (2013)

36) Rawls SM, Ding Z, Cowan A. Role of TRPV1 and cannabinoid CB1 receptors in AM 404-evoked hypothermia in rats. Pharmacol. Biochem. Behav., 83, 508-516 (2006).

37) Ayoub SS, Pryce G, Seed MP, Bolton C, Flower RJ, Baker D. Paracetamol-induced hypothermia is independent of cannabinoids and transient receptor potential vanilloid-1 and is not mediated by AM404. Drug Metab. Dispos., 39, 1689-1695 (2011). 